\title{
Development of ICSI
}

\author{
C L O’Neill, S Chow, Z Rosenwaks and G D Palermo
}

The Ronald O. Perelman and Claudia Cohen Center for Reproductive Medicine, Weill Cornell Medicine, New York, New York, USA

Correspondence should be addressed to G D Palermo; Email: gdpalerm@med.cornell.edu

This paper is part of an Anniversary Issue celebrating 40 years of in vitro fertilization. The Guest Editor for this section was Professor Lord Robert Winston.

\begin{abstract}
The first conception outside of the human body that led to the birth of Louise Brown was a tremendous accomplishment, which opened the door to the utilization of assisted reproductive techniques globally. This brought the understanding that accomplishing life in a dish required several steps, the most obvious being the timing and characteristics of fertilization. It soon became obvious in the 1980s that the most disappointing phenomenon was unexpected and complete fertilization failure. Among the approaches that were attempted to treat male factor infertility, ICSI surfaced as the technique that brought the ratio of the gametes to 1:1 and was also able to grant consistent fertilization and a higher pregnancy rate. ICSI has now been implemented for a quarter of a century, proving itself as the ultimate technique utilizing ejaculated spermatozoa independent of the semen parameters and is the sole insemination method to be used with surgically retrieved spermatozoa. There are currently various indications for ICSI that are widely adopted, rendering it the most popular insemination method worldwide. The reliability of ICSI ensures its employment in upcoming techniques involving in vitro spermatogenesis and neogametogenesis.
\end{abstract}

Reproduction (2018) 156 F51-F58

\section{The circumstances}

Without a doubt, everything started with the brave work of Bob Edwards and Patrick Steptoe (Steptoe \& Edwards 1978) whose work was crowned by the birth of Louise Brown. There is not a specific moment in time when it was made apparent that the development of advanced reproductive technologies (ART) became needed by society, but it is clear that the 1970s carried with them the need to treat tubal factor infertility.

The first conception outside of the human body was a tremendous accomplishment, which opened the door for the utilization of reproductive techniques worldwide, leading to the first IVF birth in Australia (Lopata et al. 1980) followed closely by the first IVF birth in the United States (Jones et al. 1984). The major discovery of this pioneering work was the revelation that the process of accomplishing life in a dish required several steps, the most obvious of which were the timing and characteristics of fertilization. In the 1980s, the focus shifted toward the need to broaden the indications for treatment by ART. Indeed, the major achievements of in vitro technologies brought about the focus on the actual origins of the conceptus, the gametes.

While the male reproductive cells were initially taken for granted as a constant, consistent and copious supply, this soon changed when the inability to achieve fertilization in certain cases became apparent.
This inexplicable phenomenon was certainly the key reason that led to the reconsideration of the role of the spermatozoon. This was soon observed by the first promoters of the field themselves (Cohen et al. 1984) with a series of publications offering a variety of modifications to the newly developed in vitro techniques. These modifications ranged from improved methods for selecting the spermatozoa through different ways to obtain a fraction enriched and capacitated (Mahadevan 1981, Mahadevan \& Baker 1984).

More naive approaches attempted to increase the concentration, enhance the time of exposure or even reduce the volume of the insemination medium, leading to the abandonment of the tube in favor of the more 'transparent' petri dish, where a trained eye would be able to judge the adequate number of spermatozoa added to the pool of oocytes to grant higher fertilization. This approach envisioned the interaction of the gametes like an electron quantum experiment, as if a higher number of sperm in a small volume in which all the oocytes were pooled together would somehow push one spermatozoon through the zona and grant fertilization.

\section{The development}

The 1980s ushered in a fervid attempt to radically re-approach the interaction between the two complementary gametes. These attempts ranged from 
developing methods to soften the zona pellucida (Kiessling et al. 1988), creating an actual hole into the zona using an acid Tyrode's solution (Gordon et al. 1988) or inducing a breach in the zona by making a crack or a slit in it (Cohen et al. 1988). Unfortunately, these procedures either failed to promote fertilization or created a very high number of polyspermic zygotes. These undesirable outcomes eventually led to the mixed insemination of oocytes, where some were treated in the standard in vitro fashion while others were somehow micromanipulated (Tucker et al. 1991). However, pregnancy outcomes resulting from the intrauterine transfer of embryos originating from different insemination methods were rendered inconsequential by the obvious difficulty of distinguishing the true benefits of one insemination method vs the other.

Further methods were cultivated, which opted to bypass the zona pellucida completely and insert the spermatozoon into the perivitelline space, referred to as subzonal injection (SUZI) (Fishel et al. 1990, Palermo et al. 1992a). Although this procedure was initially successful, it ultimately proved to be of limited usefulness in cases of severe male infertility, represented by impaired parameters and most importantly by dysfunctional gametes. In response, some investigators thought to bypass not only the zona pellucida but also the oolemma of the egg (Lanzendorf et al. 1988, Sathananthan et al. 1989, Ng et al. 1991). This initial work had inconsistent fertilization and unfortunately did not achieve any pregnancies. These efforts focused on treating male infertility carried out thus far led us to the development of ICSI. These endeavors were led by Gianpiero Palermo who has shared his personal recollection of the events that steered the development of intracytoplasmic sperm injection:

I was introduced to IVF during the final year of my Obstetrics and Gynecology residency when I had the chance to apply for a grant from the University of Bari that brought me to the Brussels Free University. I immediately started a Master's and Ph.D. program that gave me the basis I needed, under the appropriate mentorship, to carry on my own research project. I was told that the major hiccup of IVF was unexpected and complete fertilization failure, an unfortunate situation for couples looking to become pregnant. I immersed myself into the literature, thinking that the only way to be able to acquire as much knowledge as possible in the shortest amount of time was to devour the greatest number of publications available. The idea of working with a micromanipulator was very enticing to me, considering my inner inclination toward mechanical things. Indeed, the first manipulator I was exposed to was a Leica mechanical micromanipulator (Fig. 1), an unwieldy and coarse machine, which quickly prompted me to customize tools better adapted for the finesse of microinjection. It appeared to me from the work already in progress that the most successful procedure applied in

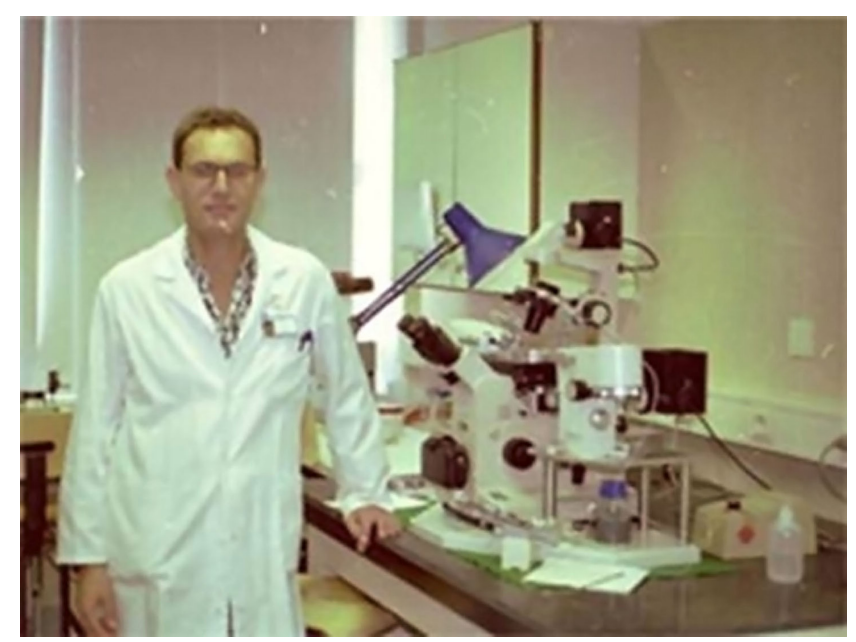

Figure 1 The inception of ICSI - Brussels, Belgium (1989). A photograph of Dr Gianpiero Palermo and his first micromanipulator, a Leica mechanical micromanipulator, with which he initially began his research at the Brussels Free University in Belgium and led to the development of intracytoplasmic sperm injection.

the clinic was subzonal injection (SUZI). In fact, partial zona dissection (PZD) did not appeal to me because in spite of the use of microsurgery, the actual insemination occurred in the standard fashion (Malter \& Cohen 1989).

I was intrigued by the sperm cell. Despite its tiny size and copious production, a single spermatozoon was as powerful as the egg itself, and as just like the egg, only one is required to initiate the development of life. After initially practicing on mouse and hamster eggs, I began my clinical work by injecting 3 into the perivitelline space (PVS) of the oocyte. To empower the sperm cell, I decided to expose them to an acrosome reaction enhancer, namely follicular fluid (Palermo et al. 1992a). The fertilization rate was satisfactory, at times $40 \%$, in part because I opted to apply SUZI only to cases that had an adequate number of spermatozoa available for use. Unfortunately, when the procedure was applied to more severe male factor cases, fertilization rates decreased to approximately $5 \%$, with considerable inconsistency. This work indicated that in declared male factor infertility cases, the spermatozoa are defective in their ability to capacitate and notably their small, or at times absent, acrosome is dysfunctional. Therefore, when the total number of sperm cells decreases, the chance of fertilization reduces accordingly. To further facilitate the interaction between the spermatozoa injected and the oocyte membrane, I created a dimple in the oolemma using the injection tool to form a 'pocket' where the sperm would then be released. While attempting this practice, I would occasionally and inadvertently pierce the membrane, allowing one spermatozoon to enter the ooplasm. I took note whenever this incident occurred and found that the oocyte almost always resulted in zygote formation. I stated to the technician working 
with me at the time, Hubert Joris, 'to leave a track in the history of medicine, we should obtain a pregnancy with intracytoplasmic sperm injection.' Hubert candidly replied 'we have it.' Hubert recalled a case with a cohort of 12 oocytes injected by SUZI, in which a spermatozoon entered into the cytoplasm of an egg where the membrane had been breached during the procedure. I had placed a question mark next to the egg on my worksheet, convinced that it would degenerate. Instead, it was the only oocyte that fertilized, which gave rise to an embryo and resulted in the first human pregnancy with intracytoplasmic sperm injection.

I soon began attempting this intracytoplasmic injection in some oocytes within each cohort of a SUZI cycle, but found it difficult to insert the sperm inside without damaging the egg. Eventually, I reached the understanding that piercing the oolemma only after a deep invagination of the membrane toward the 9 o'clock position, would grant the egg survival postinjection, one of the core methodologies of ICSI today (Palermo et al. 1996a).

The other aspect that required clarification was whether any spermatozoon, independent of quality, was capable of fertilizing an egg. I read in publications available at the time on intracytoplasmic injection used in experimental animals that a spermatozoon, presenting as immotile or dead, was still capable of fertilizing an oocyte. I thought that if there was a difference between a viable yet immotile spermatozoon and a dead cell, the only way to distinguish it would be to actually strike a motile sperm cell with the glass pipette to render it immotile and compare it to a sperm that was initially immotile within the specimen. The former contender was the one that not only fertilized but yielded consistent fertilization, defining the current ICSI protocol as it is still carried out today (Palermo et al. 1996b).

From that time forward, every case treated by SUZI had a portion of oocytes injected by ICSI, and to my surprise I found that fertilization occurred consistently in the oocytes injected into the cytoplasm (Palermo et al. 1993). The replacement of these resulting embryos provided the four pregnancies described in the first ICSI report (Palermo et al. 1992b). I could not have fathomed at the time, the role that ICSI would have in the field of reproductive medicine, nor that such an apparently simple and straightforward process would have the ability to overcome so many vulnerabilities of the male gamete (Palermo et al. 2017).'

\section{The implementation}

Upon first report of a human birth from ICSI (Palermo et al. $1992 b)$, the procedure steadily gained popularity in other European countries and from there have expanded globally. Throughout the 1990s, ICSI proved to be invaluable in assisting other procedures such as its application to the use of testicular and epididymal sperm
(Schoysman et al. 1993, Tournaye et al. 1994), which quickly came to be used for the cryopreserved forms as well (Devroey et al. 1995, Podsiadly et al. 1996). ICSI additionally proved to be useful for the fertilization of previously cryopreserved oocytes (Porcu et al. 1997) due to zona pellucida hardening upon thaw, reducing genetic contamination for embryos destined to be tested for hereditary diseases by PGD (Sermon et al. 1999), and for in vitro matured oocytes as well (Cha et al. 2000). These advances made in reproductive medicine assisted by the capabilities of ICSI propelled the utilization of the technique to a greater percentage of cases than just those concerning pure male factor.

Over 60 countries worldwide utilize ICSI as the preferred method of ART, ranging in prevalence from $55 \%$ of oocyte retrieval cycles in Asia to nearly $100 \%$ of cycles in the Middle East (Dyer et al. 2016). Initially, the indication for ICSI was simply a male factor infertility, which inhibited the spermatozoon from normally entering and fertilizing an oocyte due to either a low number of spermatozoa available, impaired motility or an abnormal morphology. However, indications for the utilization of ICSI (Fig. 2) (Pereira \& Palermo 2018) have expanded to accommodate the effects of other reproductive techniques such as the insemination of previously cryopreserved and in vitro matured oocytes, due to zona hardening hindering sperm cells from entering by natural means (Beckers et al. 1999). Additionally, ICSI is typically performed in oocytes to generate embryos that will be tested for a genetic disease or ploidy status, by PGD and PGS respectively, in order to lower the chances of sperm DNA contamination that may affect test results (Harton et al. 2011). Further, to reduce the risk between $\mathrm{HBV}, \mathrm{HCV}$, and HIV-discordant couples, ICSI is often elected, as the utilization of a single spermatozoon for insemination in conjunction with removal of the seminal fluid during sperm processing drastically reduces the chance of viral transmission (Garrido et al. 2004, Palermo et al. 2015, Wu \& Ho 2015). Additional recommendations for treatment via ICSI, some of which may be contingent on the preferences of each individual center, are low oocyte yield and maturity, dysmorphic oocytes and previous poor fertilization with standard in vitro insemination. However, one of the most unique indications for ICSI that is undoubtedly exclusive to this method of ART is the use of surgically retrieved spermatozoa for couples in which the male partner has azoospermia.

To provide some context on ICSI outcome, we can browse worldwide clinical data generated from this procedure by referencing the most recent report by the International Committee for Monitoring Assisted Reproductive Technologies, which overall resulted in a $67.4 \%$ fertilization rate, $26.8 \%$ clinical pregnancy rate and $20 \%$ delivery rate in 2010 (Dyer et al. 2016).

To provide a more intimate reference frame, over the past two and a half decades, from September 1992 


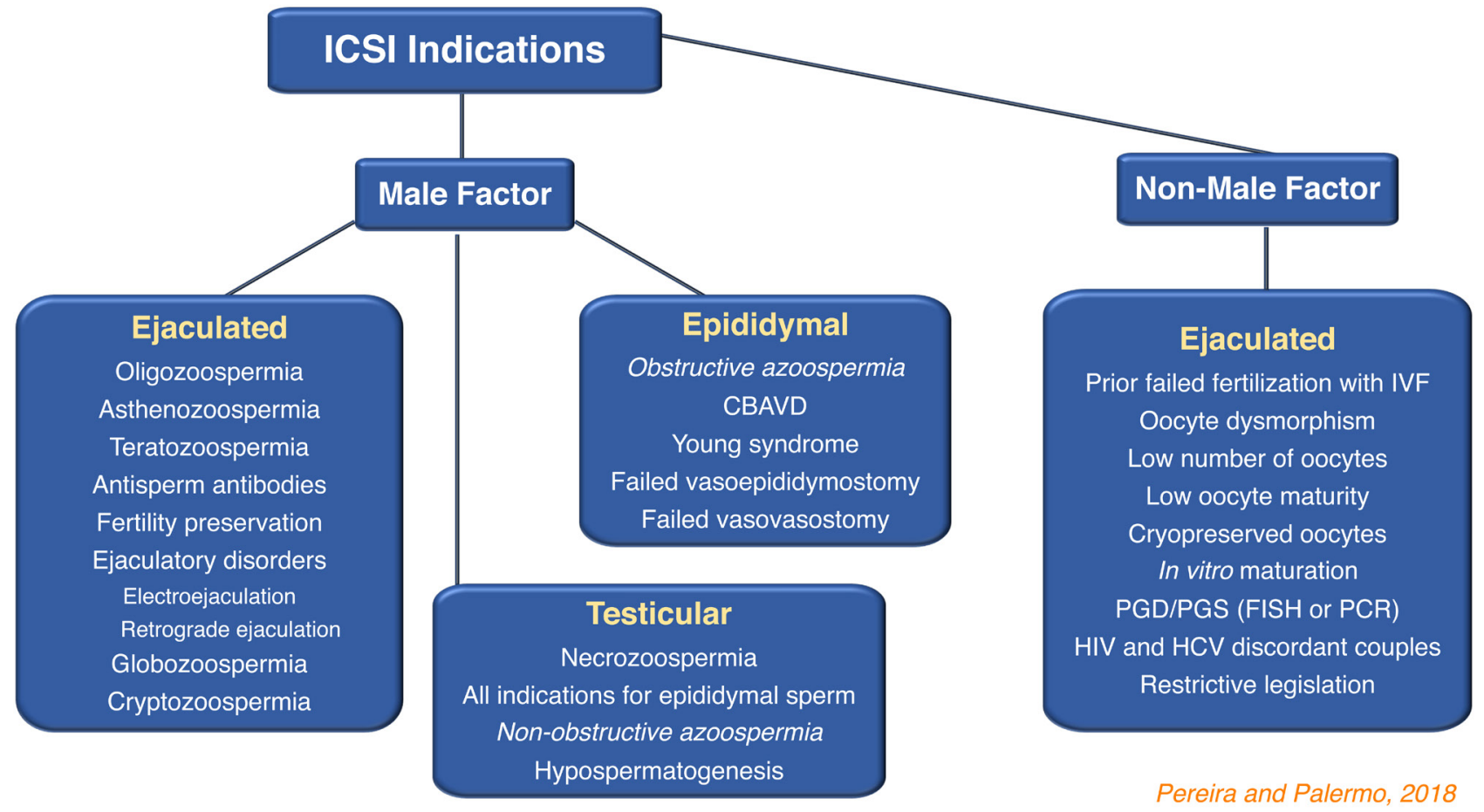

Figure 2 ICSI indications. This figure delineates the varying male and non-male factor indications for intracytoplasmic sperm injection (ICSI) that have developed over the past 25 years of the technique's existence. Indications for ICSI first began with straightforward male factor cases where the partner presented with various affections of the ejaculate specimen as listed in the figure. This insemination technique was additionally applied to more severe cases, in which a surgical retrieval of spermatozoa from the epididymis or testis was performed for the purpose of inseminating their partner's oocytes. In many centers worldwide, the indications for ICSI utilization have grown to include non-male factor cases concerning various scenarios such as failed fertilization with standard in vitro insemination or low number of oocytes retrieved, as well as in the attempt to support the integrity of accompanying techniques such as PGD or PGS on the embryo.

to June 2017, our center has performed 26,732 ICSI cycles using fresh ejaculated spermatozoa, resulting in a $75.2 \%$ fertilization rate and a clinical pregnancy rate of $41.5 \%$. Frozen ejaculated samples were used in 3702 cycles, with a comparable fertilization of $75.9 \%$ and a clinical pregnancy of $36.8 \%$ (Table 1 ). Indeed, the use of fresh and cryopreserved spermatozoa that were surgically retrieved from either the epididymis or the testis, additionally resulted in acceptable clinical pregnancy rates (Fig. 3).

In some difficult cases, concerning fresh or cryopreserved samples, there is ample sperm available for injection; yet, no motile cells are identified even after the addition of pentoxifylline, often used in an

Table 1 ICSI outcome according to semen origin.

\begin{tabular}{lrrr}
\hline Semen origin & Cycles & Fertilization $(\%)$ & $\begin{array}{c}\text { Clinical } \\
\text { pregnancies }(\%)\end{array}$ \\
\hline Fresh & & & \\
$\quad$ Ejaculate & 26,732 & $164,407 / 218,712(75.2)$ & $11,089(41.5)$ \\
$\quad$ Electro & 60 & $467 / 610(76.6)$ & $29(48.3)$ \\
$\quad$ Retrograde & 50 & $367 / 472(77.8)$ & $20(40.0)$ \\
Frozen & & & \\
$\quad$ Ejaculate & 3702 & $23,503 / 30,983(75.9)$ & $1363(36.8)$ \\
$\quad$ Electro & 26 & $180 / 262(68.7)$ & $11(42.3)$ \\
$\quad$ Retrograde & 6 & $18 / 27(66.7)$ & $1(16.7)$ \\
\hline
\end{tabular}

attempt to elicit motility, thus verifying the viability of

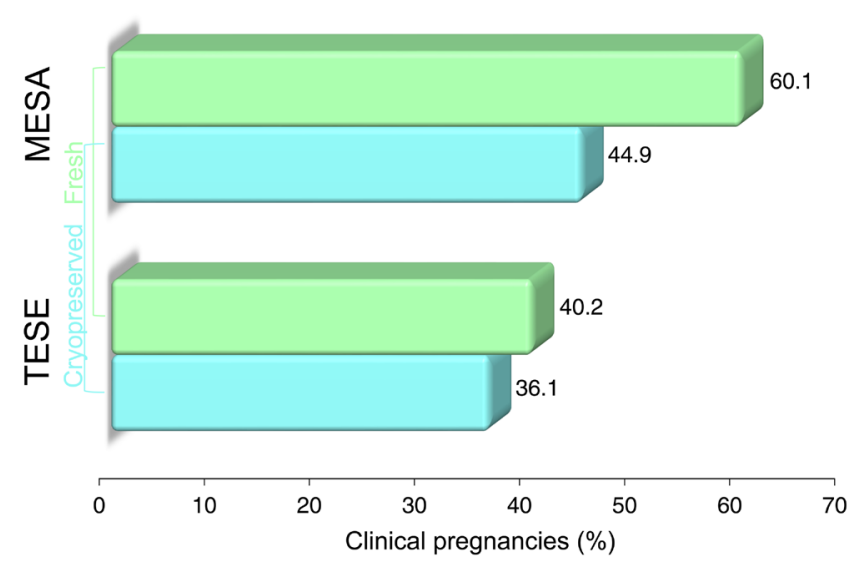

Figure 3 Clinical pregnancy rate according to the type of azoospermia and whether specimens were utilized fresh or after cryopreservation. Fresh epididymal spermatozoa (MESA) yielded a higher fertilization rate than fresh testicular (TESE) $\left(\chi^{2}, 2 \times 2,1 \mathrm{df}\right.$; $P<0.0001)$. Similarly, frozen MESA spermatozoa demonstrated higher rates of fertilization than frozen TESE $\left(\chi^{2}, 2 \times 2,1 \mathrm{df} ; P=0.001\right)$. Additionally, fresh surgical samples were found to have higher fertilization rates compared to their frozen counterparts, regardless of whether they were obtained from the epididymis $\left(\chi^{2}, 2 \times 2,1 \mathrm{df}\right.$; $P=0.0001)$ or the testicle $\left(\chi^{2}, 2 \times 2,1 \mathrm{df} ; P=0.04\right)$. 
a spermatozoon. In these difficult cases, an interesting perspective of ICSI performance concerns the embryo developmental competence following the utilization of motile, thus proven viable, vs the injection of immotile spermatozoa. Upon surveying the outcome associated with these spermatozoa, we noticed that the fertilization rate plummets significantly in ejaculated specimens from $75.6 \%$ with motile spermatozoa to $7.8 \%$ using immotile cells $(P=0.0001)$; consequently, the clinical pregnancy and delivery rates are halved (Fig. 4). A similar scenario is observed with the utilization of motile cells originating from the testis vs the immotile counterpart (55.1\% vs $17.3 \%, P=0.0001)$. However, the ensuing outcome is consequently significantly affected, resulting in lower clinical pregnancy and delivery/ongoing rates $(P=0.0001)$ for cases where spermatozoa are identified and intact, but do not display any indication of viability (Fig. 5). Although the use of immotile spermatozoa results in a poorer clinical outcome than with a motile counterpart, in about $20 \%$ of our cases, irrespective of the specimen source, ICSI generates clinical pregnancies and live offspring for men that would not have a chance of fathering a child.

\section{A look forward}

ICSI today is not only successfully used in typical male factor cases as well as for males with azoospermia, but has been instrumental in promoting the utilization of techniques such as oocyte cryopreservation (Palermo et al. 2015). It is largely used for IVM cases where the hardness of the zona and the limited number of eggs benefit from a reliable and timed insemination method. This insemination method is additionally helpful in poor responders and in older women where very few oocytes are available (Palermo et al. 2015).

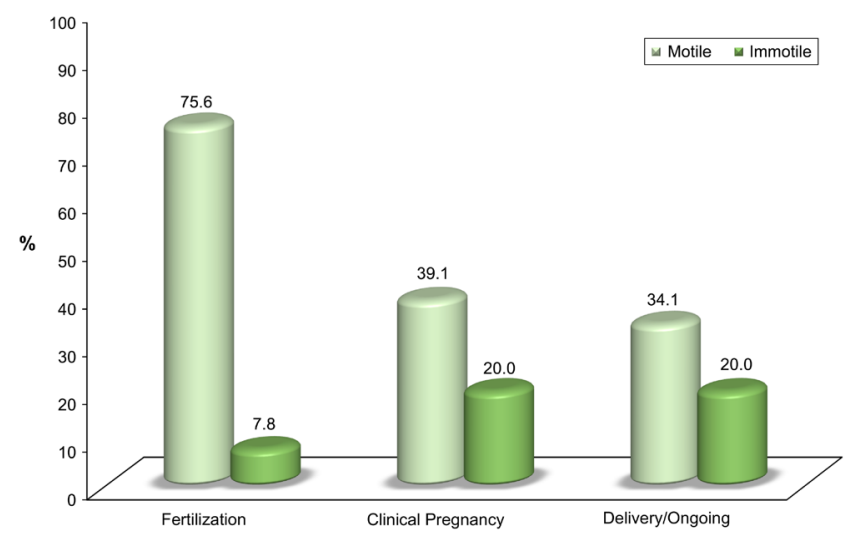

Figure 4 ICSI outcome according to the kinetic status of injected ejaculate spermatozoa. Ejaculated spermatozoa that were motile at the time of injection yielded higher fertilized conceptuses $\left(\chi^{2}, 2 \times 2,1\right.$ $\mathrm{df} ; P=0.0001)$ that resulted in apparently higher pregnancy $\left(\chi^{2}, 2 \times 2\right.$, $1 \mathrm{df} ; \mathrm{NS})$ and delivery rates $\left(\chi^{2}, 2 \times 2,1 \mathrm{df} ; \mathrm{NS}\right)$, compared to the injection of exclusively immotile cells.

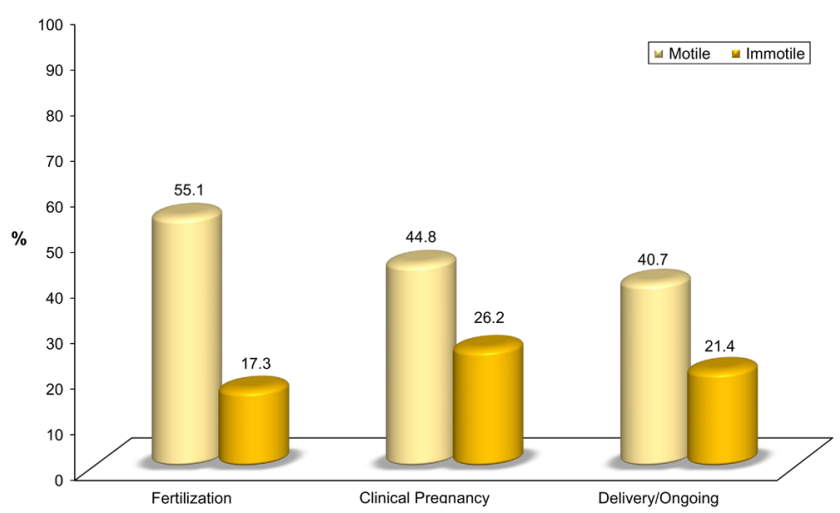

Figure $5 \mathrm{ICSI}$ outcome according to the kinetic status of injected testicular spermatozoa. Testicular spermatozoa that were motile at the time of injection yielded higher fertilized conceptuses $\left(\chi^{2}, 2 \times 2,1\right.$ $\mathrm{df} ; P=0.0001)$ that resulted in higher pregnancy $\left(\chi^{2}, 2 \times 2,1 \mathrm{df}\right.$; $P=0.0001)$ and delivery rates $\left(\chi^{2}, 2 \times 2,1 \mathrm{df} ; P=0.0001\right)$, compared to the injection of exclusively immotile cells.

The confirmation of the nuclear maturity of an oocyte involves the removal of the cumulus, and as a result, ICSI is required due to the complete exposure of the zona pellucida. Many centers prefer to use ICSI in PGD and PGS cases to lower incidences of sample contamination and similarly, ICSI has also been proposed as a choice insemination method for HIV-discordant couples to reduce chances of viral transmission.

At our center in New York, we additionally opt for ICSI in all cases involving insemination of donor eggs and in cases using frozen/thawed spermatozoa. The reason being that the specimen quality can be unpredictably poor and the incidence of unexpected fertilization failure by using standard in vitro insemination would be very difficult to explain to a couple.

In our particular practice, ICSI is applied in about $80 \%$ of total ART cases, mostly due to our role as a tertiary referral center that has a close collaboration with reproductive urologists. With ICSI, we can treat almost all couples as long as there are viable spermatozoa available. However, limitations appear, as in all ART procedures, when considering maternal age and therefore an increase in aneuploidy of the inseminated oocytes. Techniques infusing donor cytoplasm and/ or mitochondria into the oocyte are being proposed to correct this issue (Woods \& Tilly 2015), and these cases will almost certainly utilize ICSI for the insemination procedure.

A more drastic limitation occurs in cases of spermatogenic arrest as there is no source of gametes available for use leaving in vitro spermatogenesis as the only treatment option for these couples to have their own genetic child. These procedures will also require ICSI as a method of choice for use to inject in vitro-derived sperm cells (Verheyen et al. 2017). Even more dire are the cases with Sertoli-cell-only syndrome (SCOS) and germ cell aplasia, which would only benefit from 
neogametogenesis for either male or female gametes (Nagamatsu \& Hayashi 2017). While the utilization of embryonic stem cells for this method would not allow a couple to generate their own genetic child unless therapeutic cloning is used, recent advances with induced pluripotent stem cells (iPS cells) present a more appealing option in the attempt to generate genotyped gamete-like cells. This research has been embraced several years ago now by our own group and may be a reality in the near future (Palermo et al. 2002, Tsai et al. 2000). Therefore, couples with a complete absence of their own gametes may benefit from neogametogenesis to create germ cells for utilization with ICSI.

\section{Considerations}

With this brief dissertation, we hope to have provided the historical conditions that advocated for the development of a new technique to inseminate human oocytes, capable of utilizing a compromised male gamete. Several investigators had attempted to address the poor clinical outcome associated with impaired semen quality using a variety of insemination methods, but only a radical approach of depositing the sperm cell directly into the meat of the egg proved to be effective in bypassing a dysfunction of the male gamete in terms of kinetic characteristics, acrosome absence or dysmorphia, and even with a reduced soluble activating factor.

Indeed, during its development the technique required refinements that could only be interpreted through the performance of micro-manipulation of human gametes; the most important stipulation was the necessity for injection of the entire corpus of the spermatozoon and not solely the nucleus as was attempted in experimental animals.

Along with the understanding gained of material prerequisites to elicit human fertilization, ICSI required its own subtle attention to detail for a successful injection, which called upon the operator to recognize minute changes in the oocyte during the procedure that provided the signs indicative of the actual piercing of the zona pellucida and the significance of a defined injection funnel created by the pipette to grant the egg survival.

Due to the selection of an individual spermatozoon, ICSI has minimized the ramifications of classic semen parameters on reproductive ability and has additionally revealed nuances of the process of human fertilization, giving rise to the hypothesis of the paternal inheritance of the sperm centrosome and the inquiries into the importance of an oocyte activating factor (Swann 1990, Palermo et al. 1994, 1997, Parrington et al. 1996, Wolny et al. 1999, Hachem et al. 2017). Beyond low semen parameters, ICSI has also allowed even men with a complete absence of spermatozoa in the ejaculate to procreate using a more immature form of the gamete retrieved surgically from the epicenter of the male genital tract, the seminiferous tubule. Additionally, this unique insemination method has bolstered peripheral embryological protocols, giving relevance to oocyte in vitro maturation and routine use of oocyte cryopreservation.

In aggregate, this is a demonstration of the proficiency of human ingenuity within the medical field where even an inexperienced investigator, in the right settings and under appropriate guidance, is capable of offering a solution to a pressing issue, as the one presented by the lack of consistent fertilization occurring during standard in vitro insemination procedures, which prompted the development of ICSI.

The offering of new technologies, particularly in the field of human reproduction, is guided by the need of the patient or couple but should only be implemented with the support of appropriate counseling practices and the commitment toward the assurance of the safety of the offspring eventually generated, through monitoring of his or her health and developmental progress. Indeed, our team recently published a comprehensive review assessing the first follow up reports on children born from ICSI, ranging from neonates to young adults, over the past quarter of a century. These reports have described encouraging results, evidencing that ICSI children in consideration of singleton pregnancies, have physical and cognitive development comparable to that of their naturally conceived peers, as well as reassuring medical and reproductive health among the first cohorts of adolescents and young adults (Pereira et al. 2017). As the years progress, we expect to see further inquest into monitoring the reproductive abilities of the individuals generated through ICSI.

At its 40th birthday, in vitro fertilization represents a major milestone in reproductive medicine and has evolved to encompass many aspects of reproductive medicine unique to the female as well as the male. One of those aspects being the focus on treating male infertility, for which ICSI celebrates its own 25th birthday this year. Over the past quarter of a century, ICSI has granted the wish held by countless childless men, generating millions of children worldwide and presents today with an undeniable permanence and a future that appears promising.

\section{Declaration of interest}

The authors declare that there is no conflict of interest that could be perceived as prejudicing the impartiality of this review.

\section{Funding}

This research did not receive any specific grant from the public, commercial, or not-for-profit sector. 


\section{References}

Beckers NG, Pieters MH, Ramos L, Zeilmaker GH, Fauser BC \& Braat DD 1999 Retrieval, maturation, and fertilization of immature oocytes obtained from unstimulated patients with polycystic ovary syndrome. Journal of Assisted Reproduction and Genetics 16 81-86. (https://doi. org/10.1023/A:1022516806423)

Cha KY, Han SY, Chung HM, Choi DH, Lim JM, Lee WS, Ko JJ \& Yoon TK 2000 Pregnancies and deliveries after in vitro maturation culture followed by in vitro fertilization and embryo transfer without stimulation in women with polycystic ovary syndrome. Fertility and Sterility $\mathbf{7 3}$ 978-983. (https://doi.org/10.1016/S0015-0282(00)00422-2)

Cohen J, Edwards RG, Fehilly CB, Fishel SB, Hewitt J, Rowland G, Steptoe PC \& Webster J 1984 Treatment of male infertility by in vitro fertilization: factors affecting fertilization and pregnancy. Acta Europaea Fertilitatis 1510.

Cohen J, Malter H, Fehilly C, Wright G, Elsner C, Kort H \& Massey J 1988 Implantation of embryos after partial opening of oocyte zona pellucida to facilitate sperm penetration. Lancet 2 162. (https://doi.org/10.1016/ S0140-6736(88)90710-6)

Devroey P, Liu J, Nagy Z, Goossens A, Tournaye H, Camus M, van Steirteghem A \& Silber S 1995 Pregnancies after testicular sperm extraction and intracytoplasmic sperm injection in non-obstructive azoospermia. Human Reproduction 10 1457-1460. (https://doi. org/10.1093/HUMREP/10.6.1457)

Dyer S, Chambers GM, de Mouzon J, Nygren KG, Zegers-Hochschild F, Mansour R, Ishihara O, Banker M \& Adamson GD 2016 International committee for monitoring assisted reproductive technologies world report: assisted reproductive technology 2008, 2009 and 2010. Human Reproduction 31 1588-1609. (https://doi.org/10.1093/humrep/dew082)

Fishel S, Antinori S, Jackson P, Johnson J, Lisi F, Chiariello F \& Versaci C 1990 Twin birth after subzonal insemination. Lancet $335722-723$. (https://doi.org/10.1016/0140-6736(90)90834-R)

Garrido N, Meseguer M, Bellver J, Remohí J, Simón C \& Pellicer A 2004 Report of the results of a 2 year programme of sperm wash and ICSI treatment for human immunodeficiency virus and hepatitis $\mathrm{C}$ virus serodiscordant couples. Human Reproduction 19 2581-2586. (https:// doi.org/10.1093/humrep/deh460)

Gordon JW, Grunfeld L, Garrisi GJ, Talansky BE, Richards C \& Laufer N 1988 Fertilization of human oocytes by sperm from infertile males after zona pellucida drilling. Fertility and Sterility 50 68-73. (https://doi. org/10.1016/S0015-0282(16)60010-9)

Hachem A, Godwin J, Ruas M, Lee HC, Ferrer Buitrago M, Ardestani G, Bassett A, Fox S, Navarrete F, de Sutter P et al. 2017 PLC $\zeta$ is the physiological trigger of the $\mathrm{Ca}^{2+}$ oscillations that induce embryogenesis in mammals but conception can occur in its absence. Development 144 2914-2924. (https://doi.org/10.1242/dev.150227)

Harton GL, Magli MC, Lundin K, Montag M, Lemmen J \& Harper JC 2011 ESHRE PGD Consortium/Embryology Special Interest Group - best practice guidelines for polar body and embryo biopsy for preimplantation genetic diagnosis/screening (PGD/PGS). Human Reproduction 26 41-46. (https://doi.org/10.1093/humrep/deq265)

Jones HW Jr, Acosta AA, Andrews MC, Garcia JE, Jones GS, Mayer J, McDowell JS, Rosenwaks Z, Sandow BA, Veeck LL et al. 1984 Three years of in vitro fertilization at Norfolk. Fertility and Sterility 42 826-834. (https://doi.org/10.1016/S0015-0282(16)48251-8)

Kiessling AA, Loutradis D, McShane PM \& Jackson KV 1988 Fertilization in trypsin-treated oocytes. Annals of the New York Academy of Sciences 541 614-620. (https://doi.org/10.1111/j.1749-6632.1988.tb22298.x)

Lanzendorf SE, Maloney MK, Veeck LL, Slusser J, Hodgen GD \& Rosenwaks Z 1988 A preclinical evaluation of pronuclear formation by microinjection of human spermatozoa into human oocytes. Fertility and Sterility 49 835-842. (https://doi.org/10.1016/S0015-0282(16)59893-8)

Lopata A, Johnston IW, Hoult IJ \& Speirs AI 1980 Pregnancy following intrauterine implantation of an embryo obtained by in vitro fertilization of a preovulatory egg. Fertility and Sterility 33 117-120. (https://doi. org/10.1016/S0015-0282(16)44529-2)

Mahadevan M 1981 Capacitation of spermatozoa. Acta Europaea Fertilitatis 12 329-335.

Mahadevan M \& Baker G 1984 Assessment and Preparation of Semen for In Vitro Fertilization. Berlin: Springer-Verlag.
Malter HE \& Cohen J 1989 Partial zona dissection of the human oocyte: a nontraumatic method using micromanipulation to assist zona pellucida penetration. Fertility and Sterility 51 139-148. (https://doi.org/10.1016/ S0015-0282(16)60443-0)

Nagamatsu G \& Hayashi K 2017 Stem cells, in vitro gametogenesis and male fertility. Reproduction. 154 F79-F91. (https://doi.org/10.1530/REP17-0510)

Ng S-C, Bongso A \& Ratnam SS 1991 Microinjection of human oocytes: a technique for severe oligoasthenoteratozoospermia**Supported by the National University of Singapore and the National Science and Technology Board, Singapore. Fertility and Sterility 56 1117-1123. (https://doi.org/10.1016/S0015-0282(16)54726-8)

Palermo G, Joris H, Devroey P \& Van Steirteghem AC 1992a Induction of acrosome reaction in human spermatozoa used for subzonal insemination. Human Reproduction 7 248-254. (https://doi.org/10.1093/ oxfordjournals.humrep.a137626)

Palermo G, Joris H, Devroey P \& Van Steirteghem AC 1992b Pregnancies after intracytoplasmic injection of single spermatozoon into an oocyte. Lancet 340 17-18. (https://doi.org/10.1016/0140-6736(92)92425-F)

Palermo G, Joris H, Derde MP, Camus M, Devroey P \& Van Steirteghem A 1993 Sperm characteristics and outcome of human assisted fertilization by subzonal insemination and intracytoplasmic sperm injection. Fertility and Sterility 59 826-835. (https://doi.org/10.1016/S00150282(16)55867-1)

Palermo G, Munne S \& Cohen J 1994 The human zygote inherits its mitotic potential from the male gamete. Human Reproduction 9 1220-1225. (https://doi.org/10.1093/oxfordjournals.humrep.a138682)

Palermo GD, Alikani M, Bertoli M, Colombero LT, Moy F, Cohen J \& Rosenwaks Z 1996a Oolemma characteristics in relation to survival and fertilization patterns of oocytes treated by intracytoplasmic sperm injection. Human Reproduction 11 172-176. (https://doi.org/10.1093/ oxfordjournals.humrep.a019012)

Palermo GD, Schlegel PN, Colombero LT, Zaninovic N, Moy F \& Rosenwaks Z $1996 \mathrm{~b}$ Aggressive sperm immobilization prior to intracytoplasmic sperm injection with immature spermatozoa improves fertilization and pregnancy rates. Human Reproduction 11 1023-1029. (https://doi.org/10.1093/oxfordjournals.humrep.a019290)

Palermo GD, Avrech OM, Colombero LT, Wu H, Wolny YM, Fissore RA \& Rosenwaks Z 1997 Human sperm cytosolic factor triggers Ca2+ oscillations and overcomes activation failure of mammalian oocytes. Molecular Human Reproduction 3 367-374. (https://doi.org/10.1093/ molehr/3.4.367)

Palermo GD, Takeuchi T \& Rosenwaks Z 2002 Technical approaches to correction of oocyte aneuploidy. Human Reproduction 17 2165-2173. (https://doi.org/10.1093/humrep/17.8.2165)

Palermo GD, Neri QV \& Rosenwaks Z 2015 To ICSI or not to ICSI. Seminars in Reproductive Medicine 33 92-102. (https://doi. org/10.1055/s-0035-1546825)

Palermo GD, O'Neill CL, Chow S, Cheung S, Parrella A, Pereira N \& Rosenwaks Z 2017 Intracytoplasmic sperm injection: state of the art in humans. Reproduction 154 F93-F110. (https://doi.org/10.1530/REP-170374)

Parrington J, Swann K, Shevchenko VI, Sesay AK \& Lai FA 1996 Calcium oscillations in mammalian eggs triggered by a soluble sperm protein. Nature 379 364-368. (https://doi.org/10.1038/379364a0)

Pereira N \& Palermo GD 2018 Intracytoplasmic sperm injection: history, indications, technique, and safety. In Intracytoplasmic Sperm Injection: Indications, Techniques, and Applications, 1st ed., pp 9-22. Eds GD Palermo \& ES Sills. Cham, Switzerland: Springer Nature. (https://doi. org/10.1007/978-3-319-70497-5_2)

Pereira N, O'Neill C, Lu V, Rosenwaks Z \& Palermo GD 2017 The safety of intracytoplasmic sperm injection and long-term outcomes. Reproduction 154 F61-F70. (https://doi.org/10.1530/REP-17-0344)

Podsiadly BT, Woolcott RJ, Stanger JD \& Stevenson K 1996 Pregnancy resulting from intracytoplasmic injection of cryopreserved spermatozoa recovered from testicular biopsy. Human Reproduction 11 1306-1308. (https://doi.org/10.1093/oxfordjournals.humrep.a019376)

Porcu E, Fabbri R, Seracchioli R, Ciotti PM, Magrini O \& Flamigni C 1997 Birth of a healthy female after intracytoplasmic sperm injection of cryopreserved human oocytes. Fertility and Sterility 68 724-726. (https:// doi.org/10.1016/S0015-0282(97)00268-9) 
Sathananthan AH, Ng SC, Trounson A, Bongso A, Laws-King A \& Ratnam SS 1989 Human micro-insemination by injection of single or multiple sperm: ultrastructure. Human Reproduction 4 574-583. (https://doi.org/10.1093/oxfordjournals.humrep.a136946)

Schoysman R, Vanderzwalmen P, Nijs M, Segal L, Segal-Bertin G, Geerts L, van Roosendaal E \& Schoysman D 1993 Pregnancy after fertilisation with human testicular spermatozoa. Lancet 342 1237. (https://doi. org/10.1016/0140-6736(93)92217-H)

Sermon K, Seneca S, Vanderfaeillie A, Lissens W, Joris H, Vandervorst M, Van Steirteghem A \& Liebaers I 1999 Preimplantation diagnosis for fragile $\mathrm{X}$ syndrome based on the detection of the non-expanded paternal and maternal CGG. Prenatal Diagnosis 19 1223-1230. (https://doi.org/10.1002/(SICl)1097-0223(199912)19:13<1223::AIDPD724>3.0.CO;2-0)

Steptoe PC \& Edwards RG 1978 Birth after the reimplantation of a human embryo. Lancet 2 366. (https://doi.org/10.1016/S01406736(78)92957-4)

Swann K 1990 A cytosolic sperm factor stimulates repetitive calcium increases and mimics fertilization in hamster eggs. Development $\mathbf{1 1 0}$ 1295-1302.

Tournaye H, Devroey P, Liu J, Nagy Z, Lissens W \& Van Steirteghem A 1994 Microsurgical epididymal sperm aspiration and intracytoplasmic sperm injection: a new effective approach to infertility as a result of congenital bilateral absence of the vas deferens. Fertility and Sterility $\mathbf{6 1}$ 1045-1051. (https://doi.org/10.1016/S0015-0282(16)56754-5)

Tsai MC, Takeuchi T, Bedford JM, Reis MM, Rosenwaks Z \& Palermo GD 2000 Alternative sources of gametes: reality or science fiction? Human Reproduction 15 988-998. (https://doi.org/10.1093/humrep/15.5.988)
Tucker MJ, Bishop FM, Cohen J, Wiker SR \& Wright G 1991 Routine application of partial zona dissection for male factor infertility. Human Reproduction 6 676-681. (https://doi.org/10.1093/oxfordjournals. humrep.a137405)

Verheyen G, Popovic-Todorovic B \& Tournaye H 2017 Processing and selection of surgically-retrieved sperm for ICSI: a review. Basic and Clinical Andrology 27 6. (https://doi.org/10.1186/s12610-017-0050-2)

Wolny YM, Fissore RA, Wu H, Reis MM, Colombero LT, Ergun B, Rosenwaks Z \& Palermo GD 1999 Human glucosamine-6-phosphate isomerase, a homologue of hamster oscillin, does not appear to be involved in $\mathrm{Ca} 2+$ release in mammalian oocytes. Molecular Reproduction and Development 52 277-287. (https://doi.org/10.1002/ (SICl)1098-2795(199903)52:3<277::AID-MRD5>3.0.CO;2-0)

Woods DC \&Tilly JL 2015 Autologous germline mitochondrial energy transfer (AUGMENT) in human assisted reproduction. Seminars in Reproductive Medicine 33 410-421. (https://doi.org/10.1055/s-0035-1567826)

Wu MY \& Ho HN 2015 Cost and safety of assisted reproductive technologies for human immunodeficiency virus-1 discordant couples. World Journal of Virology 4 142-146. (https://doi.org/10.5501/wjv.v4.i2.142)

Received 8 January 2018

First decision 1 March 2018

Revised manuscript received 23 March 2018

Accepted 10 April 2018 